«Системні технології» 2 (127) 2020 «System technologies»

DOI 10.34185/1562-9945-2-127-2020-11

УДК 622.776

Н.С. Прядко, А.В. Бубликов, Л.В. Музыка

\title{
РАЗРАБОТКА СИСТЕМЫ АВТОМАТИЧЕСКОГО УПРАВЛЕНИЯ СТРУЙНЫМ ИЗМЕЛЬЧЕНИЕМ НА ОСНОВЕ ЭКСПЕРИМЕНТАЛЬНЫХ ДАННЯХ
}

Актуальность тематики данной работы определяется необходимостью снижения энергоемкости тонкого измельчения путем управления процессом, что предлагается осуществлять на основе результатов акустического мониторинга. В работе предложена система автоматического управления по критерию максимальной производительности, учитывающая особенности процесса. Описана функциональная и создана структурная схема измельчительной установки замкнутого цикла измельчения. Для описания прочесса подачи материала используется модель бункера с учетом изменения площади его выходного отверстия. Прочесс измельчения в рабочей зоне измельчения рассматривается как изменение концентрации материала в камере. При моделировании потока материала в классификаторе учитываются пульсации циркуляционной нагрузки в замкнутом цикле измельчения. Разработанная схема системы автоматического управления включает два уровня управления и описание объекта управления. Полученные результаты позволят качественно улучшить управление процессом измельчения.

Ключевые слова: модель, система автоматического управления, объект управления, акустические сигналы.

Введение. Эффективность производства минеральных концентратов определяется, помимо качества и объемов конечных продуктов обогащения, затратами производственных и технологических ресурсов, необходимых для их получения. Совершенствование систем управления - залог достижения максимально выгодных трендов таких параметров, как количество - качество - затраты. Движение по пути оптимизации обогатительного производства невозможно без широкого привлечения современных информационных технологий, характеризуемых широким спектром функций. На их основе создаются проблемно ориентированные информационные системы для предварительной обработки экспе-

(C) Прядко Н.С., Бубликов А.В., Музыка Л.В., 2020 
«Системні технології» 2 (127) 2020 «System technologies»

риментальной информации и создания соответствующих баз данных. Сложность и многофакторность процессов переработки полезных ископаемых в условиях реального производства накладывает существенные ограничения на возможность управления этими процессами. Поэтому, ранее полученные в Институте технической механике НАНУ и ГКАУ результаты в области акустического исследования газоструйного измельчения, создания информационной технологии и обширной базы данных позволили разработать основы управления процессом.

Постановка задачи. На сегодняшний день струйное измельчение является одним из наиболее энергоемких видов измельчения. Поэтому повышение энергоэффективности данного процесса является актуальной задачей. Вопросы выбора оптимального режима измельчения и управления процессом рассматривались давно [1-3]. Вопросам повышения эффективности работы измельчительных агрегатов посвящены труды многих советских и зарубежных авторов, в частности, в [3] описано управление процессом газоструйного измельчения на базе анализа расходнонапорных характеристик пневмотранспортной сети, давления в камере измельчения. Однако в этих случаях время запаздывания было слишком большим и максимум загрузки не удавалось удерживать.

Целью данной работы является обоснование структурной схемы системы автоматического управления струйной мельницы на основе экспериментальных исследований объекта управления и результатов акустического мониторинга зоны измельчения.

Как было показано ранее [4-5], эффективность работы струйной измельчительной установки зависит от степени загрузки измельчительной камеры и замкнутой системы измельчения в целом. Для повышения производительности $\mathrm{Q}(\mathrm{t})$ мельницы необходимо поддерживать оптимальный уровень заполнения помольной камеры. Зависимость производительности от степени заполнения носит экстремальный характер, причем надо учитывать неравномерность загрузки за счет работы системы циркуляции материала, возвращающегося в камеру для доизмельчения. Основной задачей САУ является поддержание загрузки в точке максимума производительности, но при этом необходимо избежать пере- 
«Системні технології» 2 (127) 2020 «System technologies»

грузки камеры, что ведет к «завалу» и остановке технологического процесса. Для поддержания работы системы в точке максимума необходимо управлять потоком исходного материала из бункера.

Основные исследования. Рассмотрим работу струйной мельницы в замкнутом цикле (рис. 1).

Для подачи материала используется бункер (1) с центральным телом (4) [5]. Далее загруженный материал поступает в измельчительную камеру (3) по патрубкам (2). Из камеры измельченный продукт поступает в классификатор (5), после чего готовый продукт попадает в бункер разгрузки (8) через циклон (7), а недоизмельченные классы материала по патрубкам (6) возвращаются в измельчительную камеру (3). Степень заполнения измельчительной камеры определяется акустическим датчиком, который установлен в камере (3).

При работе мельниц в замкнутом цикле их разгрузка поступает в классифицирующий аппарат, который делит его на готовый продукт и крупный продукт, который возвращают в мельницу для доизмельчения.

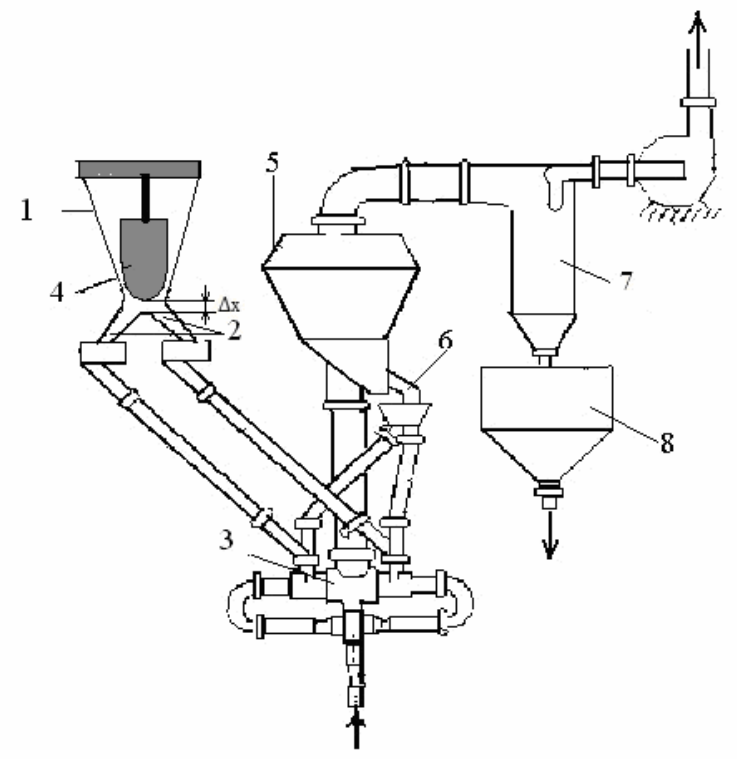

Рисунок 1 - Струйная измельчительная установка

Этот возврат крупного материала непрерывно транспортируется из классифицирующего аппарата в мельницу, проходя через нее многократно, и образует циркулирующую нагрузку мельницы которая может выражаться в виде абсолютной величины (масса в единицу времени, т/ч), 142 
«Системні технології» 2 (127) 2020 «System technologies»

либо в виде относительной величины (отношение к массе исходного материала, подаваемого в мельницу в единицу времени, \%, доли ед.).

Для разработки системы управления необходимо учитывать следующие особенности процесса:

- в качестве регулирующего параметра необходимо использовать изменение концентрации материала в камере измельчения;

- производительность мельницы в зависимости от концентрации материала при постоянном расходе энергоносителя имеет один экстремум;

- экстремум производительности приходится на оптимальный уровень концентрации материала в мельнице, дальнейшее повышение концентрации ведет к снижению производительности, а затем к остановке процесса;

- основным возмущающим воздействием при измельчении являются физико-механические свойства материала;

- наличие запаздывания при прохождении исходного материала по каналам подачи.

Рассматриваемый процесс подвержен воздействию внешних возмущений и обладает внутренней стохастической составляющей. Однако экспериментальные данные показали, что внешние возмущения приложены на входе и их роль, а также роль внутренней стохастической составляющей процесса относительно незначительна. Главную роль в изменении переменных состояний играет широкое использование рециклов в данных процессах, вследствие чего в замкнутых циклах возникают длительные (по сравнению, например, со временем дискретной загрузки) и достаточно гладкие переходные процессы.

Проведенными ранее экспериментальными исследованиями установлены связи технологических параметров процесса измельчения различных материалов и характеристик акустических сигналов зоны измельчения [5, 7]. Созданная база данных позволила выделить характеристики акустических сигналов, соответствующих оптимальной загрузке камеры измельчения. Зависимость средней амплитуды сигналов рабочей зоны от концентрации материала в камере выражается полиномом 4 
«Системні технології» 2 (127) 2020 «System technologies»

степени. Однако при установившемся режиме измельчения эта зависимость является квадратичной функцией с коэффициентами, зависящими от свойств материала и технологических параметров процесса. В частности, для измельчения шамота уравнение имеет вид:

$$
\mathrm{A}_{\mathrm{cp}}(\mathrm{t})=-0,0062(\mathrm{Q}(\mathrm{t}) / \mathrm{G}(\mathrm{t}))^{2}+0,2141 \mathrm{Q}(\mathrm{t}) / \mathrm{G}(\mathrm{t})-0,4046 ; \mathrm{R}=0,846,
$$

где $\mathrm{Q}(\mathrm{t})$ - производительность мельницы по готовому продукту, $\mathrm{G}(\mathrm{t})$ масса загрузки в единицу времени.

Эта зависимость использовалась для контроля концентрации материала в камере измельчения.

Для разработки системы автоматического управления рассматриваем процесс измельчения как процесс изменения концентрации массы материала. Тогда через бункер загрузки поступает дискретно G(t), кг/ч материала. Разработанный управляемый загрузочный конусообразный бункер имеет внутри задвижку овальной формы («оживайло»), движение которой вверх описывается уравнением:

$$
G(t)=S(t) \lambda \sqrt{3,2 g \frac{\pi R_{2}^{2}-S(t)}{2 \sqrt{\pi S(t)}}},
$$

где $\mathrm{S}(\mathrm{t})$ - текущая площадь выходного отверстия, R2 - максимальный радиус бункера, $\lambda$ - коэффициент скольжения для сыпучих материалов. Для конкретного бункера процесс загрузки материала описывается функцией $G(S(t))$, причем время загрузки мало относительно времени измельчения.

Изменение концентрации материала в камере измельчения зависит от новой загружаемой массы $\mathrm{G}(\mathrm{t})$ и массы материала, поступающего для повторного измельчения (циркулирующей нагрузки), т.е. $\mathrm{GBX}(\mathrm{t})=\mathrm{G}(\mathrm{t})+\mathrm{C}(\mathrm{t})$. Эта масса составляет концентрацию $(\theta$, отн. ед.) материала в камере измельчения. В общем случае зависимость $Q=Q(\theta)$ квадратичная функцией. Для измельчения шамота по данным экспериментов при давлении энергоносителя $\mathrm{P}=0,3$ МПа и числе оборотов классификатора n=600 мин-1 уравнение изменения концентрации в мельнице имеет вид: 
«Системні технології» 2 (127) 2020 «System technologies»

$$
\mathrm{QM}(\mathrm{t})=-62,14 \mathrm{G}_{\text {вx }}^{2}(\mathrm{t})+89,1 \mathrm{G}_{\text {вх }}(\mathrm{t})-17,77
$$

При управлении замкнутым циклом измельчения необходимо учитывать работу классификатора, который отделяет из потока материала готовый продукт, поступающий в бункер выгрузки, и недоизмельченный материал, составляющий циркулирующую нагрузку. Для определения уравнения классификатора исследовалось измельчение узкой фракции шамота $(-1,0+1,4)$, а не смеси фракций. Тогда уравнение классификатора выражается линейной зависимостью $\mathrm{Q}=\mathrm{Q}(\mathrm{G})$. Для шамота это уравнение имеет вид:

$$
Q(t)=0,82 G(t)-0,02
$$

Проведенные исследования позволили разработать структурную схему системы автоматического управления измельчительной установки (см. рис. 2).

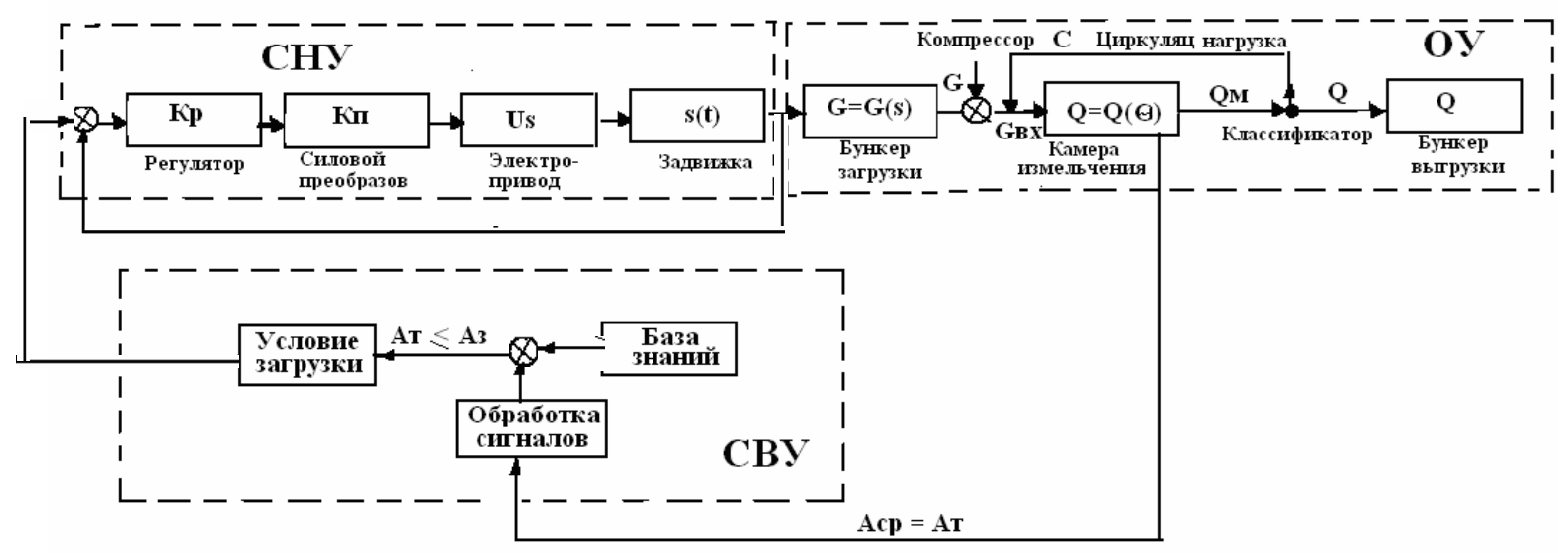

Рисунок 2 - Структурная схема САУ струйной мельницы

Схема включает объект управления (ОУ) - бункер загрузки, мельницу, классификатор и бункер выгрузки готового продукта, систему нижнего уровня (СНУ) и систему верхнего уровня (СВУ). СНУ включает элементы системы управления бункера загрузки. Загрузочный бункер имеет центральное тело, соединенное с силовым приводом и двигающимся вдоль оси. Силовой привод состоит из соленоида, ферромагнитного сердечника, пружины обратного хода и силового преобразователя.

Для получения сигнала управления силовым приводом проводится анализ акустических сигналов зоны измельчения в СВУ. Сигнал задания (Аз) формируется экспериментально по результатам «Базы данных», ISSN 1562-9945 (Print) 
«Системні технології» 2 (127) 2020 «System technologies»

исходя из типа, крупности исходного материала, готового продукта и технологических условий измельчения. Для осуществления акустического мониторинга в измельчительной камере устанавливается волновод, который соединен с пьезокерамическим датчиком. Датчик фиксирует столкновения измельчаемых частиц с волноводом и преобразует энергию столкновения в электрический сигнал. Текущие сигналы (Ат) непрерывно записываются по выработанной методике мониторинга [8] и передаются в СВУ в блок обработки сигналов, далее проводится сравнение текущих сигналов с заданными (см. рис. 2). В случае совпадения акустических характеристик (в частности, амплитуд) текущих сигналов с заданными из базы знаний подается сигнал в СНУ на Регулятор и включается система управления бункером. Это значит, что режим измельчения вышел за пределы оптимального - изменилась концентрация в камере измельчения: либо недостаточно материала, либо перегрузка материалом. В первом случае открывается задвижка, и материал подается из бункера, во втором случае задвижка закрывается, и подача материала в камеру прекращается. Быстродействие задвижки определяется инерционностью соленоида и исполнительного механизма и превышает время цикла измельчения на порядок. Это позволяет сделать систему управления струйным измельчением эффективной.

Выводы. Разработана структурная схема системы автоматического управления струйной мельницы на основании экспериментальных данных. Определены исходные уравнения, описывающие изменение концентрации материала в элементах установки. На основе предложенной схемы разработана и проходит опробование система автоматического управления струйной установкой на основе контроля концентрации материала в помольной камере по результатам акустического мониторинга. Данная система управления позволит качественно улучшить управление процессом измельчения.

\section{ЛИТЕРАТУРА / ЛІТЕРАТУРА}

1. Марюта А.Н. Автоматическая оптимизация процесса обогащения руд на магнитно-обогатительных фабриках. М.: Недра, 1975.- 231 с. 
«Системні технології» 2 (127) 2020 «System technologies»

2. Gokcen H.S. The effect of grinding aids on dry micro fine grinding of feldspar/H.S.Gokcen, S.Cayirli, Y.Ucbas, K.Kayaci //International Journal of Mineral Processing.-Volume 136, 2015, Pp. 42-44.

3. Горобец В.И., Горобец Л.Ж. Новое направление в струйном измельчении. Днепропетровск 1974 г. - 241 с.

4. Pryadko N. Optimization of fine grinding on the acoustic monitoring basis// Energy Efficiency Improvement of Geotechnical Systems.- 2015 Taylor \& Francis Group, London, p. 99 - 108.

5. Pryadko N., Muzyka L., Strelnikov H., Ternova K. Acoustic method of jet grinding study and control // E3S Web of Conferences 109, 00074 (2019) Essays of Mining Science and Practice 2019 p.111https://doi.org/10.1051/e3sconf/201910900074

6. Патент на корисну модель № 112112 Україна, МПК В02С 25/00. Газоструминний млин / Прядко Н.С.Музика Л.В.; заявник і патентоволодар Інститут технічної механіки НАНУ і ДКАУ. - u 201603419; заявл. 04.04.2016; опубл. 12.12.2016, Бюл. № 13. - 7 с.

7. Muzyka L.V., Pryadko N.S., Strelnikov H.A., Grenev A.F. Control of mass flow in jet mill on base of acoustic monitoring //Naukovyi Visnyk Natsionalnoho Hirnychoho Universytetu. - 2019. - № 4. - P. 5-10. http://nv.nmu.org.ua/index.php/ru/ DOI: 10.29202/nvngu/2019-4/3

8. Музыка Л.В., Прядко Н.С., Стрельников Г.А. Система контроля и регулирования работы газоструйной измельчительной установки для повышения ее производительности // Техническая механика №2, 2018, C. 113-125.

\section{REFERENCES}

1. Maryuta A.N. Automatic optimization of the ore beneficiation process at magnetic processing plants. M .: Nedra, 1975.-231p.

2. Gokcen H.S. The effect of grinding aids on dry micro fine grinding of feldspar/H.S.Gokcen, S.Cayirli, Y.Ucbas, K.Kayaci //International Journal of Mineral Processing.-Volume 136, 2015, Pp. 42-44.

3. Gorobets V.I., Gorobets L.Zh. A new trend in jet grinding. Dnepropetrovsk 1974,-241p. 
«Системні технології» 2 (127) 2020 «System technologies»

4. Pryadko N. Optimization of fine grinding on the acoustic monitoring basis// Energy Efficiency Improvement of Geotechnical Systems. - 2015 Taylor \& Francis Group, London, p. 99 - 108.

5. Pryadko N., Muzyka L., Strelnikov H., Ternova K. Acoustic method of jet grinding study and control // E3S Web of Conferences 109, 00074 (2019) Essays of Mining Science and Practice 2019 p.111https://doi.org/10.1051/e3sconf/201910900074

6. Patent №112112 Ukraine, Jet Grinding Mill.- publ.12.12.2016,bul.№13.-7p. 7. Muzyka L.V., Pryadko N.S., Strelnikov H.A., Grenev A.F. Control of mass flow in jet mill on base of acoustic monitoring //Naukovyi Visnyk Natsionalnoho Hirnychoho Universytetu. - 2019. - № 4. - Pp. 5-10. http://nv.nmu.org.ua/index.php/ru/ DOI: 10.29202/nvngu/2019-4/3

8. Muzyka L.V., Pryadko N.S., Strelnikov G.A. System for monitoring and regulating the operation of a gas-jet grinding plant to increase its productivity// Tech. mech. №2, 2018, Pp. 113-125.

\section{Received 17.02.2020. Accepted 19.02.2020. \\ Разработка системы автоматического управления струйным измельчением на основе экспериментальных данных}

Актуальность тематики данной работы определяется необходимостью снижения энергоемкости тонкого измельчения путем управления процессом, что предлагается осуществлять на основе результатов акустического мониторинга. В работе предложена система автоматического управления по критерию максимальной производительности, учитывающая особенности процесса. Описана функциональная и создана структурная схема измельчительной установки замкнутого цикла измельчения. Для описания процесса подачи материала используется модель бункера с учетом изменения площади его выходного отверстия. Процесс измельчения в рабочей зоне измельчения рассматривается как изменение концентрации материала в камере. При моделировании потока материала в классификаторе учитываются пульсации циркуляционной нагрузки в замкнутом цикле измельчения. Разработанная схема системы автоматического управления включает два уровня управления и описание объекта управления. Полученные результаты позволят качественно улучшить управление процессом измельчения.

Automatic control system of jet grinding based on experimental data

The relevance of the paper subject is determined by the need to reduce the fine grinding energy consumption by process control proposed to be carried out on the basis of the results of acoustic monitoring.

The problem of choosing the optimal grinding mode and control methods have been considered for a long time. The work of many Soviet and foreign authors is devoted to questions of improving the grinding units efficiency, in particular, they used the control of gas-jet grinding based on the analysis of flow-pressure characteristics of the pneumatic transport network, pres- 


\section{«Системні технології» 2 (127) 2020 «System technologies»}

sure in the grinding chamber. However, in these cases, the delay time was too long and the maximum load could not be maintained.

The aim of this work is to justify the structural scheme of the automatic control system of a jet mill based on experimental studies of the control object and the results of acoustic monitoring of the grinding zone

The efficiency of the jet grinding plant depends on the loading degree of the grinding chamber and the closed grinding system as a whole. To increase mill productivity, it is necessary to maintain an optimal fill level of the grinding chamber. The dependence of productivity on the filling degree is extreme, and it is necessary to take into account the uneven loading due to the operation of the material circulation system. It is proposed to realize this on the basis of the acoustic signal analysis of the grinding zone.

The paper proposes an automatic control system on maximum performance criterion, taking into account the process features. It is described the functional and created a structural diagram of a grinding plant for a closed grinding cycle. To describe the material supply process, a hopper model is used taking into account changes in its outlet area. The operation process in the grinding zone is considered as a change of material concentration in the chamber. For material flow modeling in the classifier, circulation load pulsations in a closed grinding cycle are taken into account. The developed scheme of the automatic control system includes two control levels and a control object description. The results allow qualitatively improving the control of the grinding process.

Прядко Наталия Сергеевна - д.т.н., с.н.с., ведущий научный сотрудник, Институт технической механики НАН Украины и ГКА Украины.

Бубликов Андрей Викторович - к.т.н.доцент кафедры автоматизации и приборостроения, Национальный технический университет «Днепровская политехника».

Музыка Лев Владимирович - младший научный сотрудник, Институт технической механики НАН Украины и ГКА Украины.

Прядко Наталія Сергіївна - д.т.н., с.н.с., провідний науковий співробітник Інституту технічної механіки НАН України і ДКА України.

Бубліков Андрій Вікторович - к.т.н., доцент кафедри автоматизації та приладобудування, Національний технічний університет «Дніпровська політехніка».

Музика Лев Володимирович - молодший науковий співробітник Інституту технічної механіки НАН України і ДКА України.

Pryadko Nataliya - Leading Researcher, Institute of Technical Mechanics of the National Academy of Sciences of Ukraine and State Space Agency of Ukraine, Doctor of Technical Sciences.

Bublikov Andrey - PhD, Associate Professor, National Technical University «Dniprovska Politechnika».

Muzyka Lev- Junior Researcher, Institute of Technical Mechanics of the National Academy of Sciences of Ukraine and State Space Agency of Ukraine. 